\title{
Biodegradable and Transparent Films With Tunable UV-blocking Property From Xylose Residue by a Top-down Approach
}

\section{Yijia Song}

Beijing Forestry University

\section{Sheng Chen}

Beijing Forestry University

\section{Yanglei Chen}

Beijing Forestry University

\section{Yanglei Xu}

Beijing Forestry University

Feng Xu ( $\nabla$ xfx315@bjfu.edu.cn )

Beijing Forestry University https://orcid.org/0000-0003-2184-1872

\section{Research Article}

Keywords: Xylose residue, UV-blocking films, Top-down fabrication, Delignification, Regeneration

Posted Date: February 11th, 2021

DOI: https://doi.org/10.21203/rs.3.rs-217910/v1

License: (9) This work is licensed under a Creative Commons Attribution 4.0 International License. Read Full License

Version of Record: A version of this preprint was published at Cellulose on July 16th, 2021. See the published version at https://doi.org/10.1007/s10570-021-03994-5. 
1 Biodegradable and Transparent Films with Tunable UV-Blocking Property

2 from Xylose Residue by a Top-Down Approach

3 Yijia Song, Sheng Chen*, Yanglei Chen, Yanglei Xu, Feng Xu*

4

5 Beijing Key Laboratory of Lignocellulosic Chemistry, Beijing Forestry University, No. 35 Tsinghua East Road,

$6 \quad$ Beijing, 100083, China

7

8

*Corresponding author:

9 shengchen@bjfu.edu.cn (Sheng Chen); xfx315@bjfu.edu.cn (Feng Xu)

10 Tel/Fax: +86-10-62337993

11 


\section{Abstract}

13 As over exposure of the earth to ultraviolet (UV) light and increased amount of petroleum-based plastic waste,

14 biodegradable UV-blocking materials are desired for diverse sustainable applications. Xylose residue, as the 15 byproduct of xylitol production from corn cobs, is mainly composed of cellulose and lignin. Here, we develop a 16 series of xylose residue films through a top-down approach (i.e., tunable delignification and regeneration) without 17 any additional additives. The treated xylose residues with lignin content of $4.4-29.7 \%$ are used to prepare 18 regenerated films, which exhibit excellent UV-blocking capability: 68.6-99.2\% for UVB (290-320 nm) and 47.198.2\% for UVA (320-400 nm). Moreover, these films remain a great optical transparency (50.6-86.6\%) and show enhanced water vapor permeability $\left(2.17-2.76 \times 10^{-11} \mathrm{~g} \cdot \mathrm{cm}^{\cdot} \mathrm{cm}^{-2} \cdot \mathrm{s}^{-1} \cdot \mathrm{mmHg}^{-1}\right)$, surface hydrophobicity (water contact angle $=72.3-86.4^{\circ}$ ), and thermal stability. Overall, our sustainable UV-blocking films have potential applications in the fields of electronics, food packaging, and windshields, etc. This study provides new insights into converting xylose residue directly to high value-added functional bioproducts.

Keywords: Xylose residue, UV-blocking films, Top-down fabrication, Delignification, Regeneration 
As the depletion of stratospheric ozone in recent decades, excessive ultraviolet (UV) radiation, including UVA (320-400 nm) and UVB (280-320 nm), results in greater damage to plants, animals, and even outdoor devices on the earth's surface(Calvo et al. 2012; Sasani Ghamsari et al. 2017; Williamson et al. 2014; Yang et al. 2019). Therefore, UV-blocking films have attracted increased attention from researchers for applications in diverse fields, such as electronics, food packaging, and windshields(Babaei-Ghazvini et al. 2018; Gause and Chauhan 2016; Shen et al. 2020; Yun et al. 2010). Nowadays, a variety of UV-blocking films have been developed with great properties(Bahramian 2020; Cohen et al. 2017b; Guo et al. 2017; Hu et al. 2020; Wang et al. 2012; Zhou et al. 2020). However, conventional UV-blocking films are mainly based on petroleum-based polymers, such as polyethylene (PE)(Zhou et al. 2020), polyethylene terephthalate (PET)(Bahramian 2020; Guo et al. 2017), polypropylene (PP)(Cohen et al. 2017b), and polyurethane (PUR)(Wang et al. 2012). These materials are nonsustainable and non-biodegradable, which may have a shortage of feedstock resources and lead to serious secondary pollution in the nature. Furthermore, introducing functional materials, i.e. UV blockers, is the most common method to endow films with UV blocking property. To date, many organic agents (such as benzotriazole and benzophenone derivatives) and inorganic agents (such as $\mathrm{TiO}_{2}$ and $\mathrm{ZnO}$ ) have been widely used to fabricate UV-blocking films(Cohen et al. 2017a; Neamjan et al. 2012; Parejo et al. 2006). Wang et al. fabricated a transparent cellulose film containing $2.95 \mathrm{wt} \% \mathrm{CeO}_{2}$ nanoparticles, which exhibited desired UV shielding properties(Wang et al. 2019). Similarly, Cohen et al. developed a PP film embedded with polymeric benzotriazole nanoparticle; it decreased UV transmission from $95 \%$ to $0 \%$ (Cohen et al. 2017a). Nevertheless, most of organic UV protection agents are unstable and toxic(Koetke et al. 2010); inorganic nanoparticles are easily agglomerated, which have a negative effect on the anti-ultraviolet performance of films(Althues et al. 2007). All these problems limited the large-scale industrial production and wide practical applications of UV-blocking films.

Recently, various biomass-derived materials have been recognized as a potential candidate compared to petroleum-based materials due to their environmental friendliness and biodegradability(Chen et al. 2016; Dutta et al. 2009; Fu et al. 2015; Galindez et al. 2019). As an agriculture residue in xylitol-production industry, xylose residue is the abundant, easily available, and renewable bioresource. In the whole world, a large number of xylose residue are obtained as by-products of xylitol annually. For example, approximately 23 million ton of xylose residue are produced each year in China(Guo et al. 2018). However, most of them were discarded as wastes and could not be utilized in high value-added fields(Zhang et al. 2012). It remains a challenge to convert xylose residue 
Xylose residue is mainly composed of cellulose and lignin. Cellulose, the most abundant natural polymer in nature, has been widely used in various fields due to its many merits, such as renewability, biocompatibility, and biodegradability(Sadeghifar et al. 2016; Zhu et al. 2018). Lignin, as the natural aromatic material, possesses conjugated structures and unsaturated systems, which endows lignin with many excellent properties, such as UV blocking property, thermal stability, oxidation resistance, and hydrophobicity. Therefore, the combination of cellulose and lignin is a promising and feasible approach to prepare sustainable UV-blocking materials. The bottom-up approach by mixing cellulose and lignin have been reported to fabricate UV-blocking materials; however, the poor dispersion of lignin in the composite and the complex process hindered their large-scale production. Since xylose residue consists of both cellulose and lignin, the direct fabrication of UV-blocking films from xylose residues through a top-down method would be dramatically promising.

Herein, for the first time, we prepared flexible and sustainable UV-blocking films based on xylose residue without any additional additives via a facile top-down approach: tunable delignification and direct regeneration. The obtained films exhibited highly effective UV-shielding capability but remained a great optical transparency. Their morphological and chemical structures were analyzed. In addition, the xylose residue films showed great water vapor barrier property, thermal stability, mechanical behavior, and surface hydrophobicity, mainly due to the original nature of lignin. This work sought to demonstrate the effect of delignification on the properties of UVblocking films, and further provide new insights into the development of sustainable functional materials based on biological macromolecules.

\section{Materials and methods}

\section{Materials}

Xylose residue was obtained from Longlive Biotechnology Co. Ltd. (Shandong, China). It was washed with water by sonication for $30 \mathrm{~min}$ and dried in an oven at $60{ }^{\circ} \mathrm{C}$ for $12 \mathrm{~h}$. Then, the clean xylose residue was crushed by a grinder and picked out through a sieve with 80 meshes per square inch. The ionic liquid, 1-ethyl-3methylimidazolium acetate ([Emim]Ac), was purchased from Chengjie Chemistry Co., Ltd. (Shanghai, China). Sodium hydroxide was purchased from Macklin Biochemical Co., Ltd. (Shanghai, China).

\section{Fabrication of sustainable ultraviolet-blocking films}

The fabrication process of the UV-blocking films was illustrated in Fig. 1. In industry, corn cobs were used to produce xylitol, remaining a large amount of xylose residue (Residue 1). After partial delignification by $2 \% \mathrm{NaOH}$ at $80{ }^{\circ} \mathrm{C}$ with the solid to liquid ratio of $1: 10$, the residue 2 that was mainly composed of cellulose and lignin was 
converted into the mixture with different lignin content $(4.4 \%, 9.6 \%, 19.5 \%$, and $29.7 \%)$. Subsequently, approximately $5 \mathrm{wt} \%$ residue was directly dissolved in [Emim]Ac under magnetic stirring at $90{ }^{\circ} \mathrm{C}$ for about 2 hours. The obtained uniform xylose residue/ILs solutions were degassed in vacuum oven and casted on a smooth and flat glass plate. After regeneration though immersing in deionized water to remove ionic liquid and drying in oven at $60{ }^{\circ} \mathrm{C}$ for $12 \mathrm{~h}$, the xylose residue films were finally obtained.

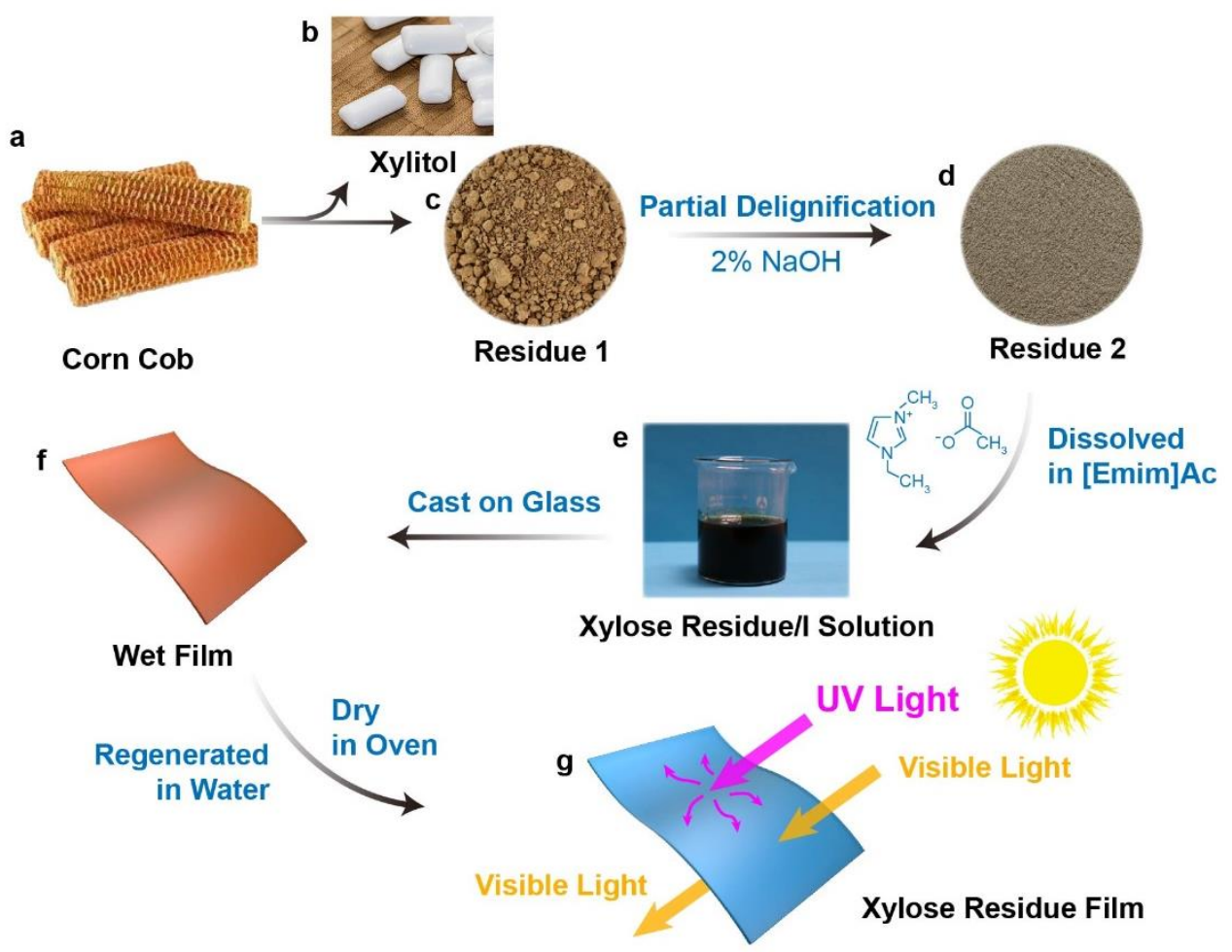

92

Fig. 1 The schemes showing the fabrication process of xylose residue films

\section{Characterization}

The as-prepared films were coated with gold-palladium in a sputter coater (Hitachi E-1010, Japan) and then observed with a scanning electron microscope (SEM, JMS-7401, Japan) at acceleration voltages of $3 \mathrm{kV}$. Fourier transform infrared (FTIR) spectrometer (Nicolet iN10-MX, Thermo Scientific) equipped with an attenuated total reflectance (ATR) was utilized to study the chemical structure of films. A total of 32 cumulative scans were taken in the transmittance mode, with a resolution of $4 \mathrm{~cm}^{-1}$ in the region of 4000-600 $\mathrm{cm}^{-1}$. The crystalline structure of native xylose residue, cellulose film and xylose residue films was studied by X-ray diffraction analyzer (XRD, D8 Advance, Bruker) equipped with Ni-filtered $\mathrm{Cu} \mathrm{K \alpha} \alpha_{1}$ radiation $\left(\lambda=0.154 \mathrm{~nm}\right.$ ). The scattering range was $5-40^{\circ}$ at an increment of $0.05^{\circ}$ with a scanning rate of $8^{\circ} \mathrm{min}^{-1}$. 

in the wavelength range $200-600 \mathrm{~nm}$, which revealed the transparency and UV-blocking feature of films. The blocking percentage for UVB (280-320 nm) and UVA (320-400 nm) was calculated by eqn. (1) and (2), respectively:

$$
\begin{aligned}
& \text { UVB blocking }(\%)=100-\frac{\int_{280}^{320} T(\lambda) d(\lambda)}{\int_{280}^{320} d(\lambda)}(\%) \\
& \text { UVA blocking }(\%)=100-\frac{\int_{320}^{400} T(\lambda) d(\lambda)}{\int_{320}^{400} d(\lambda)}(\%)
\end{aligned}
$$

Where $T(\lambda)$ is the average spectral transmittance of the films, $d(\lambda)$ is the bandwidth, and $\lambda$ is the wavelength. The water vapor permeability (WVP) of films was determined following the standard ASTM E 96/E 96M. The test film was sealed to a $10 \mathrm{ml}$ beaker containing $12 \mathrm{~g}$ anhydrous calcium chloride. The device was dried at $105{ }^{\circ} \mathrm{C}$ for $24 \mathrm{~h}$ at beginning of the experiment. To maintain an $85 \%$ relatively humidity (RH) gradient, saturated $\mathrm{KCl}$ solution was placed in desiccator at $25^{\circ} \mathrm{C}$. The WVP was calculated following the eqn. (3):

$$
\mathrm{WVP}=\frac{\mathrm{qd}}{t s \Delta P}
$$

Where $q / t$ is the slope of the weight increase versus time $(\mathrm{g} / \mathrm{s}), d$ is the thickness $(\mathrm{cm})$ of the film, $s$ is the area of the film which is exposed to humidity condition $\left(4.91 \mathrm{~cm}^{2}\right), \Delta P$ is the difference of the vapor pressure between the two sides of films $(23.76 \mathrm{mmHg})$. Three replicates were measured for each sample.

Surface wettability of the obtained films was measured by a water contact angle (WCA) meter (SL200KS, Kino). A drop of deionized water about $10 \mu \mathrm{L}$ was placed on the surface of films from a micro-syringe. The film samples $\left(1 \times 3 \mathrm{~cm}^{2}\right)$ were fixed on the movable sample plate leveled horizontally before measurement. The measurements were repeated three times for each sample. The mechanical properties of the films were measured using Zwick Z005 with a $100 \mathrm{~N}$ load cell at room temperature. The thickness of films should be tested with a micrometer (Lorentzen and Wettre, precision $1 \mu \mathrm{m}$ ) before measurements. The samples were cut in the rectangular specimens of $10 \mathrm{~mm}$ long and $40 \mathrm{~mm}$ wide, and at least five replicate specimens were tested from each film. Thermal stability of the films was characterized by thermogravimetric analysis (TGA) using a thermogravimetric analyzer (TG/DTA6300, Seiko) under a $\mathrm{N}_{2}$ atmosphere from 50 to $600{ }^{\circ} \mathrm{C}$ with a heating rate of $10^{\circ} \mathrm{C} / \mathrm{min}$.

\section{Results and discussion}

\section{Componential and morphological analysis}

Lignin contents in the delignificated xylose residue treated by $2 \% \mathrm{NaOH}$ were tuned via changing reaction time (0-3 h), which may be attributed to that a suitable concentration of $\mathrm{NaOH}$ can break the bond between lignin and 
carbohydrate(Chahal 1983). As shown in Supplementary Fig. S1, the lignin content in xylose residue decreased from $29.7 \%$ to $1.2 \%$ with the reaction time increased from 0 to $3 \mathrm{~h}$. The initial treatment in the first $1 \mathrm{~h}$ exhibited apparent effect on the delignification of xylose residue. However, further prolonging the treatment time to $3 \mathrm{~h}$ had a limited effect on decreasing lignin content in xylose residue, which may be contributed that the reaction has already reached an equilibrium state in the first $1 \mathrm{~h}$. After treatment for 8,30 , and $60 \mathrm{~min}$, the xylose residues with the lignin of $19.5 \%, 9.6 \%$, and $4.4 \%$ were obtained, respectively. These residues and the untreated one with $29.7 \%$ lignin were selected as raw materials for the fabrication of the UV-blocking films. The films were referred as F29.7, F-19.5, F-9.6, and F-4.4. For comparison, the pure cellulose based regenerated film was also prepared and referred as F-Cell.

The morphology of xylose residue films was critical to their properties, such as transparency, surface wettability and mechanical strength. The photographs of F-Cell, F-9.6, and F-29.7 were presented in Fig. 2a-c. As can be seen, the F-Cell showed a high optical transparency, which was demonstrated by the clearly identified printed text under the film. Although the xylose residue films of F-9.6 and F-29.7 had a yellow-brown color, they also exhibited a great optical transparency; this was essential to their practical applications as UV-blocking films in a wide range.

The surficial and cross-sectional morphology of films were further investigated by SEM. The F-Cell displayed a smooth and neat surface (Fig. 2d). However, F-9.6 and F-29.7 showed a relatively rough surfaces (Fig. $2 \mathrm{e}, \mathrm{f}$ ), which was probably attributed to the existence of lignin. On the other hand, as shown by the cross-sectional images of films (Fig. 2g-i), the F-9.6 and F-29.7 possessed roughly but densely laminated structures than the FCell, which may be due to the hydrophobic property of lignin(Petridis et al. 2011). 


\section{F-Cell}
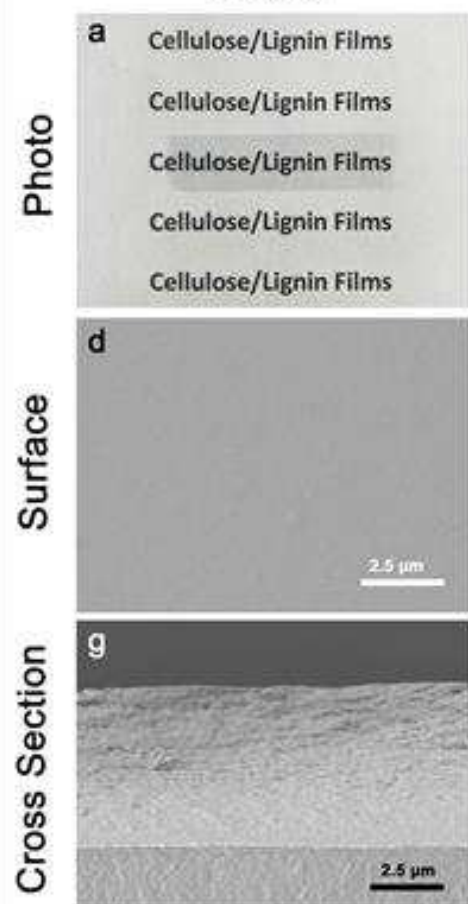

F-9.6

b Cellulose/Lignin Films Cellulose/Lignin Films Cellulose/tignin Films Cellulose/Lignin Films Cellulose/Lignin Films
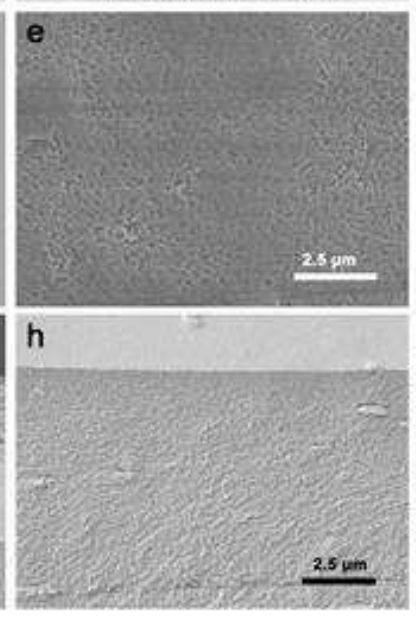

\section{F-29.7}

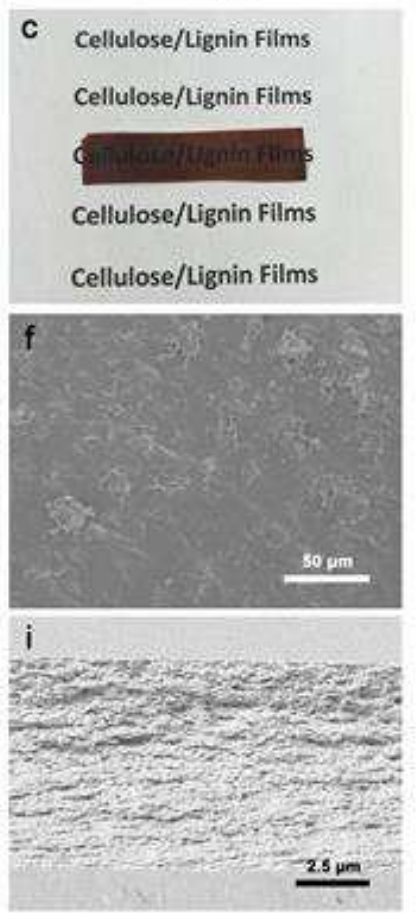

Fig. 2 (a-c) Photos of F-Cell, F-9.6, and F-29.7 placed close to the printed pattern underneath. (d-f) The surface morphologies of F-Cell, F-9.6, and F-29.7. (g-i) The cross-sectional morphologies of F-Cell, F-9.6, and F-29.7

\section{Chemical and crystalline structure}

FT-IR spectra of the regenerated films are shown in Fig. 3a. The F-Cell and all xylose residue films had obvious absorbances associated with cellulose. The bands at 3359 and $2891 \mathrm{~cm}^{-1}$ are attributed to $\mathrm{O}-\mathrm{H}$ stretching and $\mathrm{C}-\mathrm{H}$ stretching. A small absorbance at $1421 \mathrm{~cm}^{-1}$ is assigned to the symmetric bending of $\mathrm{CH}_{2}$. The bands at 1370,1315 and $1152 \mathrm{~cm}^{-1}$ correspond to the $\mathrm{O}-\mathrm{H}$ bending, $\mathrm{C}-\mathrm{H}$ bending and $\mathrm{C}-\mathrm{O}$ anti-symmetric stretching, respectively. The absorbance at $1046 \mathrm{~cm}^{-1}$ could be attributed to the C-O-C stretching on the pyran ring. A small sharp band at 893 $\mathrm{cm}^{-1}$ is ascribed to the $\beta$-glucosidic linkages between glucose in cellulose. In addition, the spectra of xylose residue films exhibited characteristic bands of lignin at $1602,1514,1453$ and $833 \mathrm{~cm}^{-1}$, which are assigned to the aromatic skeletal vibrations and C-O stretching in lignin(Liu et al. 2008). Furthermore, the absorption intensity of these bands was enhanced with the increased lignin content. The crystalline structure of raw xylose residue and asprepared films was evaluated by XRD patterns and illustrated in Fig. 3b. The raw xylose residue displayed characteristic peaks at $15.5^{\circ}, 22.2^{\circ}$, and $34.5^{\circ}$ - corresponding to (110), (110), (200) and (004) crystal plane, respectively—which belonged to the typical diffraction of cellulose I(Ling et al. 2018). After dissolving by 

according to the diffraction peaks at $12.1^{\circ}(1 \overline{1} 0)$ and $20.1^{\circ}(110)$. These results reveal that the cellulose I

crystalline structure was completely disappeared and cellulose macromolecules were recrystallized as cellulose II after dissolution in ILs followed by regeneration in deionized water. In addition, the crystallinity of regenerated films decreased compared with raw xylose residue.
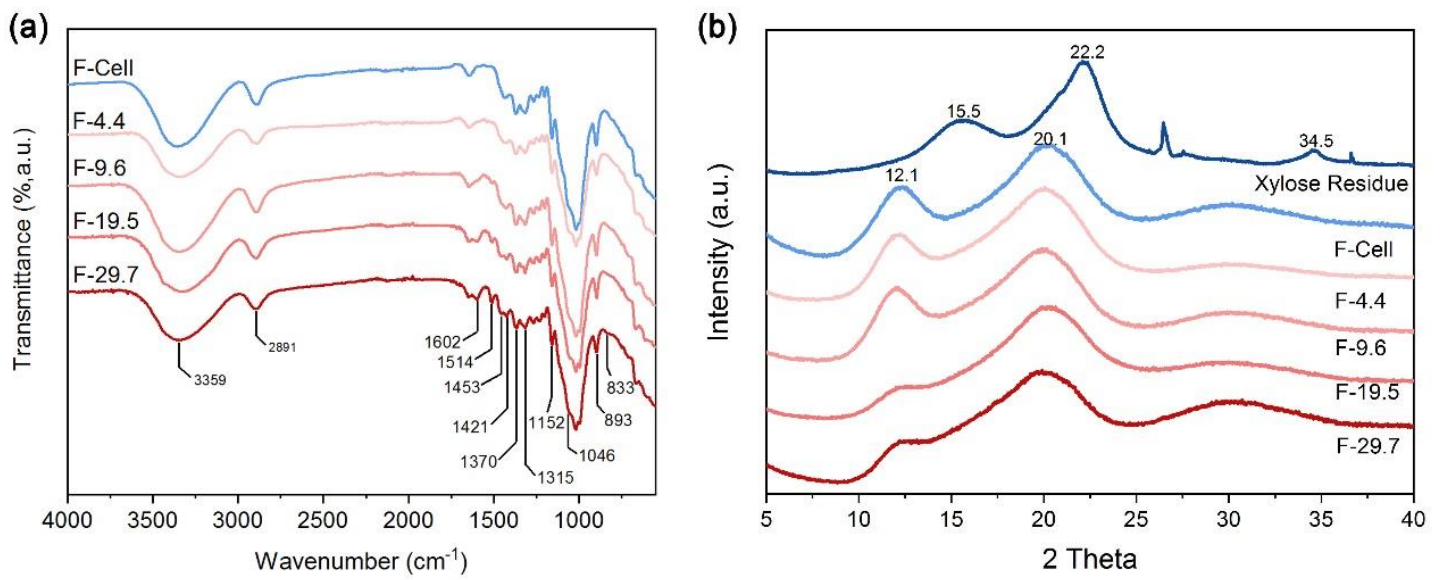

Fig. 3 (a) FTIR spectra and (b) XRD patterns of F-Cell, F-4.4, F-9.6, F-19.5, and F-29.7

\section{UV-blocking and water vapor barrier performance}

The UV blocking capability are important for broadening the films' potential applications. Fig. 4a shows the optical properties of regenerated films based on cellulose and xylose residue. As can be seen, F-Cell exhibited a high transmittance of $90.1 \%$ at $600 \mathrm{~nm}$. The as-prepared xylose residue films of F-4.4, F-9.6, F-19.5 and F-29.7 exhibited relatively lower transmittances of $86.6 \%, 75.9 \%, 68.7 \%$ and $50.6 \%$ at $600 \mathrm{~nm}$, respectively due to the increased content of lignin. Long wavelength UVA with strong penetrating ability, affecting the human health; UVB, in contrast, with shallower penetration depth, also cause much harmful impact and potential risk of skin cancer(Ling et al. 2020). As expected, all the xylose residue films showed excellent UV blocking capability in both UVA and UVB range, when compared to the F-Cell. The UVB and UVA blocking percentage for each film are presented in Fig. 4b. F-Cell had a relatively low value of UV blocking capacity (barely 17.0\% for UVB and $14.1 \%$ for UVB) owing to the absence of functional groups for UV shielding. A striking difference was noted that as-prepared xylose residue films, including F-9.6, F-19.5 and F-29.7, showed strong UV blocking performance. Tuning the films by different content of lignin lead to the different UV blocking capability. The UVB blocking performance for F-4.4, F-9.6, F-19.5, and F-29.5 were 68.6\%, 98.4\%, 99.2\%, and 99.2\%, respectively. The UVA 
blocking performance also exhibited similar results for F-4.4 (47.1\%), F-9.6 (87.6\%), F-19.5 (93.9\%), and F-29.5 (98.2\%). This may be related to the phenylpropane-based structure or hydroxyphenyl groups of lignin in ultraviolet region( $\mathrm{Li}$ et al. 2019a). Taken together, these results suggest that the xylose residue films have promising prospects for application in UV blocking.
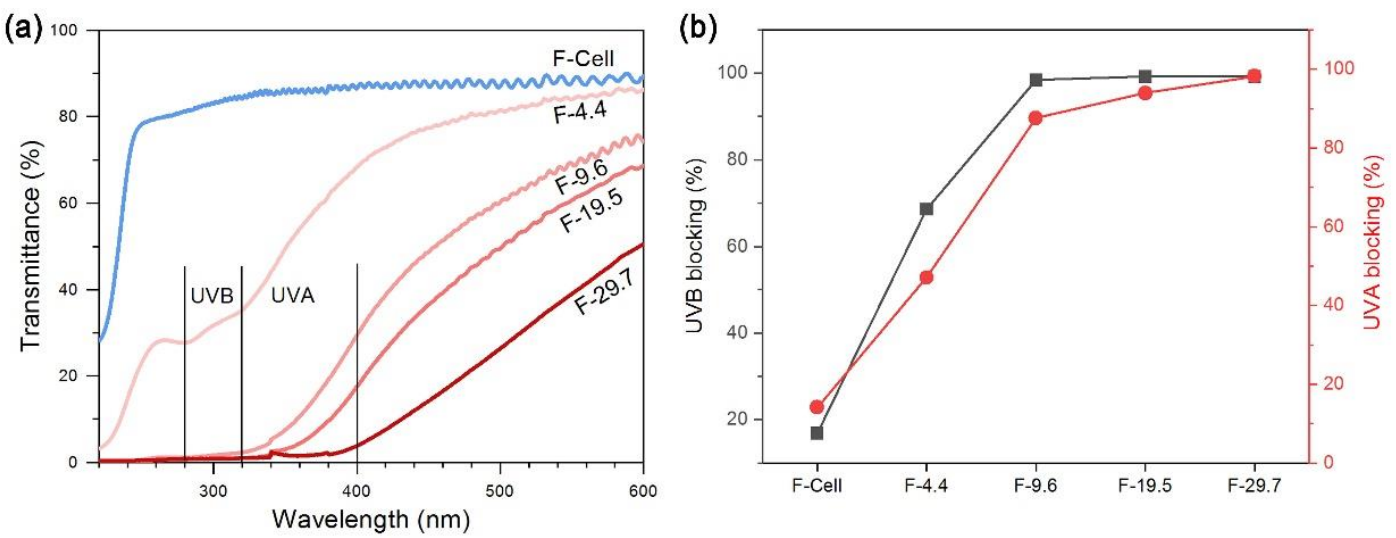

Fig. 4 (a) Optical transmission spectra and (b) UV blocking rate of F-Cell, F-4.4, F-9.6, F-19.5, and F-29.7

Water vapor permeability (WVP) is another important parameter of films for various fields. Especially for food packaging applications, the value of WVP should be as low as possible to maintain the food quality. Table 1 shows the WVP of films with different lignin content. The results implied that the WVP of xylose residue films were lower than that of pure cellulose film. With the increase of lignin content, the regenerated xylose residue films exhibited a better barrier property. This result could be explained by the intermolecular interaction between lignin and cellulose that hindered the way for water vapor to diffusion(Shankar et al. 2015). Furthermore, the laminated structures mentioned by SEM images could also result in less permeation of water vapor.

Table 1 Water vapor permeability of regenerated cellulose and xylose residue films

\begin{tabular}{cc}
\hline Sample & WVP \\
& $\left(\times 10^{-11} \mathrm{~g} \cdot \mathrm{cm} \cdot \mathrm{cm}^{-2} \cdot \mathrm{s}^{-1} \cdot \mathrm{mmHg}^{-1}\right)$ \\
\hline F-Cell & $3.36 \pm 0.37$ \\
F-4.4 & $2.76 \pm 0.11$ \\
F-9.6 & $2.71 \pm 0.26$ \\
F-19.5 & $2.67 \pm 0.37$ \\
F-29.7 & $2.17 \pm 0.10$ \\
\hline
\end{tabular}


The surface wettability and hydrophobicity are significant for substrates toward wide applications. Herein, the surface wettability of different films was investigated by contact angle and shown in Fig. 5. The F-Cell showed a WCA of $66.8^{\circ}$, while the xylose residue films of F-4.4, F-9.6, F-19.5, and F-29.7 showed a WCA of $72.3^{\circ}, 76.2^{\circ}$, $80.5^{\circ}$ and $86.4^{\circ}$, respectively. The increase of hydrophobicity of xylose residue films was mainly due to the aromatic structure and the fewer hydroxyl groups of lignin compared to cellulose(Llevot et al. 2016). Moreover, amount of lignin in films can hinder the formation of hydrogen bonding from the free hydroxyl group and water molecules(Bian et al. 2018). In addition, the WCA of prepared xylose residue films was constant as the time increased, which proved the excellent stability of films' surface structure.

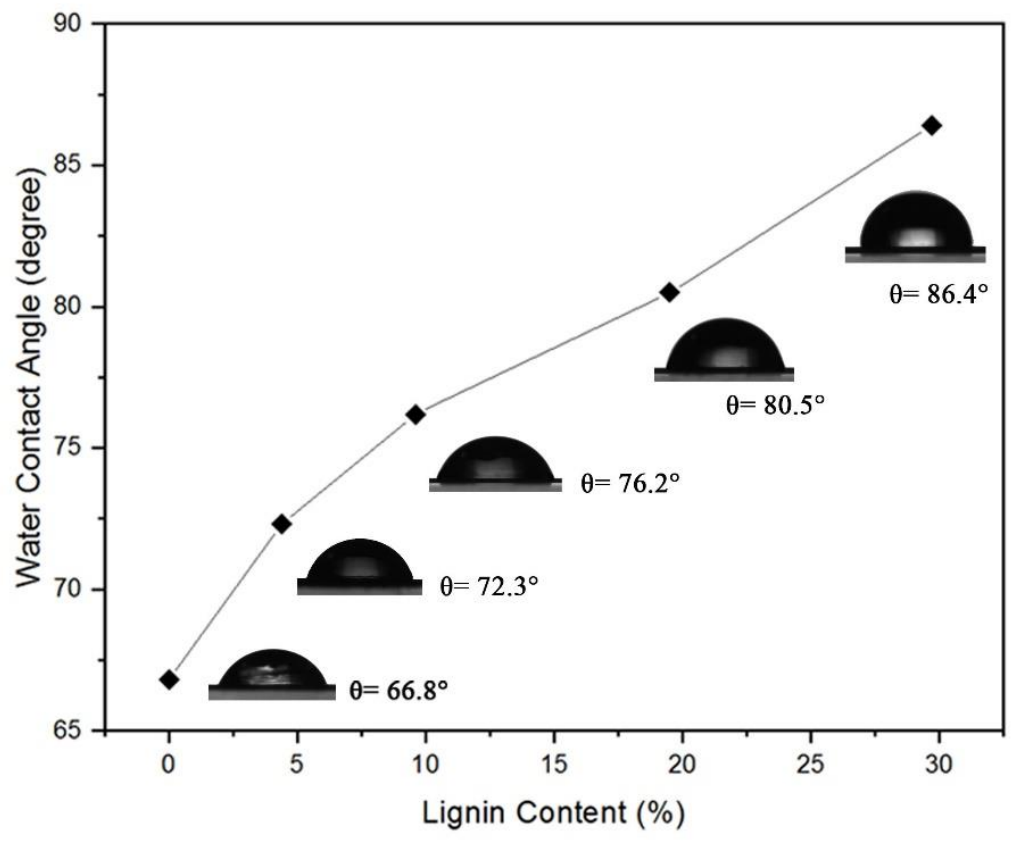

Fig. 5 The WCA of F-Cell, F-4.4, F-9.6, F-19.5, and F-29.7

The mechanical properties like strength and toughness of films were further tested to ensure that the films have sufficient physical performance. The stress-stain curves of the regenerated cellulose film and xylose residue films are shown in Fig. 6a. The mechanical properties including tensile strength, tensile strain, and toughness of as-prepared films are also summarized in Supplementary Table S1. As can be seen, the F-Cell had a tensile stress of $70.63 \pm 2.91 \mathrm{MPa}$, which attributed to the original great performance of native cellulose fiber. For four xylose residue films of F-4.4, F-9.6, F-19.5 and F-29.7, they had relatively lower tensile strength of $66.49 \pm 5.28 \mathrm{MPa}$, 54.95 $\pm 0.18 \mathrm{MPa}, 45.86 \pm 1.89 \mathrm{MPa}$ and $42.27 \pm 2.39 \mathrm{MPa}$, respectively. These results suggested that lignin have a negative impact on the film's tensile strength, which may be due to the lignin's interference of hydrogen bonding formation between cellulose fibers in composite films(Bian et al. 2018). However, the tensile strength of obtained 

tensile strengths of 20-40 MPa(Li et al. 2019b). In Fig. 6b, the xylose residue films possessed a lower toughness but much higher stiffness compared with F-Cell, which may be attributed to the rigid structure of lignin. From the SEM images in Fig. 2h-i, the poor mechanical strength of xylose residue films might be relevant to their layered structures caused by the hydrophobicity of lignin particles. In addition, low crystallinity shown in XRD patterns could be another reason for the poor mechanical performance results(Harris and Lee 2008). Therefore, various films with tunable UV-blocking and mechanical properties via tunable delignification and regeneration could obtained and used in different application.

(a)

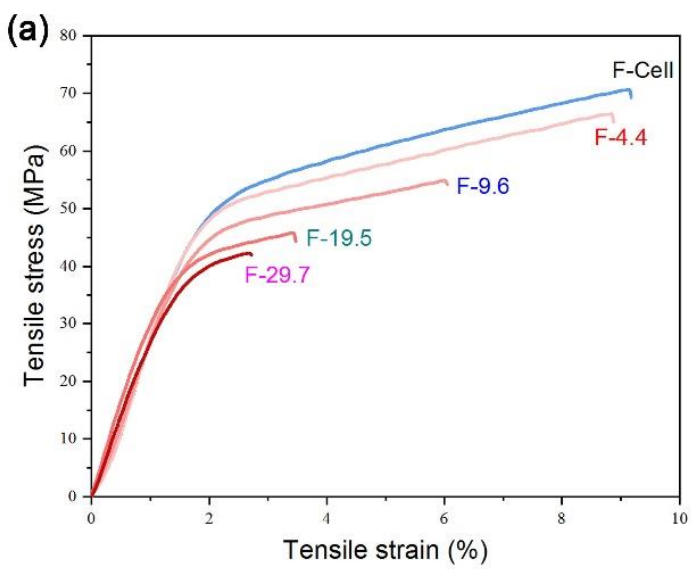

(b)

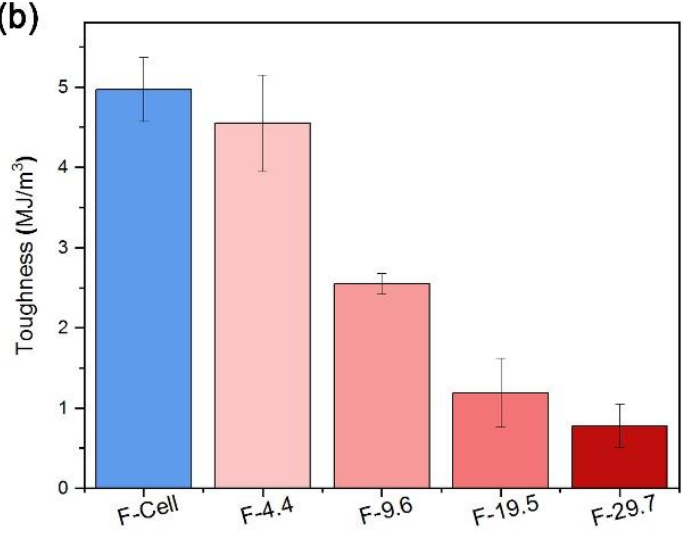

Fig. 6 (a)Tensile stress-strain curves and (b) toughness comparison of F-Cell, F-4.4, F-9.6, F-19.5, and F-29.7

The thermal stability of the regenerated films was investigated using TGA and DTG analysis under a nitrogen atmosphere. As Fig. 7a shows, all the films exhibited two steps of degradation. The first weight loss occurred below $200{ }^{\circ} \mathrm{C}$ due to the release of water. In the range of $200-600{ }^{\circ} \mathrm{C}$, the rate of decomposition and mass weight of regenerated films were maximum, which was mainly due to the degradation of cellulose. Evidently, the amount of remaining solid residue at $600{ }^{\circ} \mathrm{C}$ of the five regenerated films were $15.52 \%, 17.88 \%, 18.02 \%, 21.57 \%$, and $25.41 \%$, respectively, which implied that the thermal stability of the xylose residue films was improved with the increase of lignin content. Besides, the $\mathrm{T}_{\text {onset }}$ (the temperature at onset of the decomposition of polymer), $\mathrm{T}_{\max }$ (the maximum weight loss temperatures), and the residue values of the films were determined from the DTG curves as shown in Table 2. Obviously, F-29.7 showed the highest $\mathrm{T}_{\text {onset }}$ of $251.42{ }^{\circ} \mathrm{C}$ and $\mathrm{T}_{\max }$ of $345.99^{\circ} \mathrm{C}$ compared to other films, indicating that lignin has a positive effect on the thermal behavior of films(Sadeghifar et al. 2016). The increased thermal stability of films makes the xylose residue films a promising candidate for applications in electronic, energy, sensing, and other high-tech fields. 

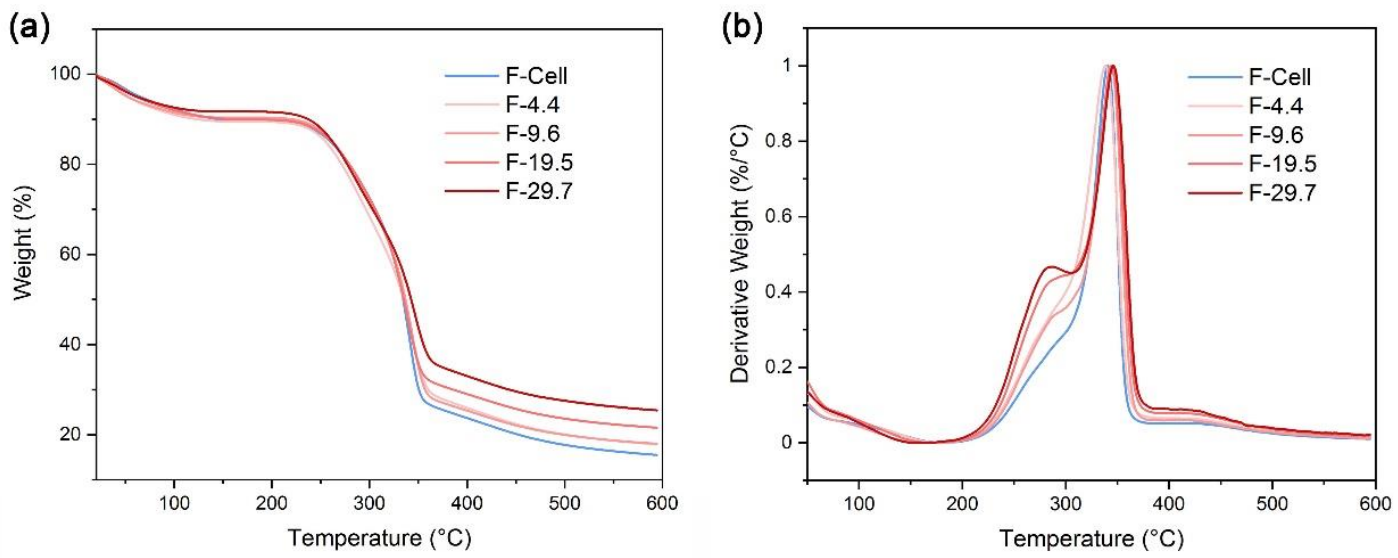

Fig. 7 (a)TGA and (b) DTG curves of F-Cell, F-4.4, F-9.6, F-19.5, and F-29.7

Table 2 Thermal characteristics of TG curves in Fig. 7

\begin{tabular}{cccccc}
\hline Curve & F-Cell & F-4.4 & F-9.6 & F-19.5 & F-29.7 \\
\hline $\mathrm{T}_{\text {onset }}\left({ }^{\circ} \mathrm{C}\right)$ & 243.88 & 246.55 & 249.31 & 250.00 & 251.42 \\
$\mathrm{~T}_{\max }\left({ }^{\circ} \mathrm{C}\right)$ & 340.81 & 338.96 & 343.87 & 343.95 & 345.99 \\
Residue (wt\%) at $600{ }^{\circ} \mathrm{C}$ & 15.52 & 17.88 & 18.02 & 21.57 & 25.41 \\
\hline
\end{tabular}

\section{Conclusion}

In summary, the biodegradable and flexible UV-blocking films have been fabricated based on xylose residue via the top-down tunable delignification and regeneration. Taking advantage of the original lignin, the obtained xylose residue films possessed excellent UV-blocking property (68.6-99.2\% for UVB and 47.1-98.2\% for UVA) and great optical transmittance (50.6-86.6\%). They also exhibited enhanced water vapor barrier property, surface wettability, and thermal stability when compared to pure cellulose films. In addition, the xylose residue films showed a better tensile strength than that of most of petroleum-based films, satisfying the commercial demands. Therefore, our sustainable UV-blocking films based on xylose residue have great potential and prospects for diverse applications, such as flexible electronics, food packaging, and windshields. This work provides a new perspective on converting xylose residue directly to high value-added functional materials.

\section{Acknowledgements}


271 The authors gratefully acknowledge the financial support from the Hot-Spots Tracking Project of Beijing Forestry 272 University (No. 2019BLRD12).

Appendix A. Supplementary data

275 Effect of reaction time on the delignification of xylose residue; the mechanical properties of as-prepared 276 regenerated cellulose film and xylose residue films. (PDF)

\section{Compliance with ethical standards}

279 Conflict of interest: The authors declare that they have no conflict of interest.

280 
Althues H, Henle J, Kaskel S (2007) Functional inorganic nanofillers for transparent polymers. Chem Soc Rev 36:1454-1465. doi:10.1039/b608177k

Babaei-Ghazvini A, Shahabi-Ghahfarrokhi I, Goudarzi V (2018) Preparation of UV-protective starch/kefiran/ZnO nanocomposite as a packaging film: Characterization. Food Packaging and Shelf Life 16:103-111. doi:10.1016/j.fpsl.2018.01.008

Bahramian A (2020) Poly(ethylene terephthalate)-based nanocomposite films as greenhouse covering material: Environmental sustainability, mechanical durability, and thermal stability. Journal of Applied Polymer Science doi:10.1002/app.49991

Bian H, Gao Y, Wang R, Liu Z, Wu W, Dai H (2018) Contribution of lignin to the surface structure and physical performance of cellulose nanofibrils film. Cellulose 25:1309-1318. doi:10.1007/s10570-018-1658-x

Calvo ME, Castro Smirnov JR, Míguez H (2012) Novel approaches to flexible visible transparent hybrid films for ultraviolet protection. Journal of Polymer Science Part B: Polymer Physics 50:945-956. doi: $10.1002 /$ polb. 23087

Chahal DS (1983) Growth Characteristics of Microorganisms in Solid State Fermentation for Upgrading of Protein Values of Lignocelluloses and Cellulase Production. In: Foundations of Biochemical Engineering. ACS Symposium Series. pp 421-442. doi:10.1021/bk-1983-0207.ch020

Chen G-G, Qi X-M, Guan Y, Peng F, Yao C-L, Sun R-C (2016) High Strength Hemicellulose-Based Nanocomposite Film for Food Packaging Applications. ACS Sustainable Chemistry \& Engineering 4:1985-1993. doi:10.1021/acssuschemeng.5b01252 
Cohen, Haham H, Pellach M, Margel S (2017a) Design of UV-Absorbing Polypropylene Films with Polymeric Benzotriaziole Based Nano- and Microparticle Coatings. ACS Appl Mater Interfaces 9:868-875. doi:10.1021/acsami.6b12821

Cohen S, Kolitz-Domb M, Haham H, Gelber C, Margel S (2017b) Engineering of UV-absorbing polypropylene films containing poly(2-(2'-hydroxy-5'-methacryloxyethylphenyl)-2H-benzotriazole) nanoparticles.

Polymers for Advanced Technologies 28:897-904. doi:10.1002/pat.3994

Dutta PK, Tripathi S, Mehrotra GK, Dutta J (2009) Perspectives for chitosan based antimicrobial films in food applications. Food Chemistry 114:1173-1182. doi:10.1016/j.foodchem.2008.11.047

Fu F, Li L, Liu L, Cai J, Zhang Y, Zhou J, Zhang L (2015) Construction of cellulose based ZnO nanocomposite films with antibacterial properties through one-step coagulation. ACS Appl Mater Interfaces 7:25972606. doi:10.1021/am507639b

Galindez A, Daza LD, Homez-Jara A, Eim VS, Vaquiro HA (2019) Characterization of ulluco starch and its potential for use in edible films prepared at low drying temperature. Carbohydr Polym 215:143-150. doi:10.1016/j.carbpol.2019.03.074

Gause S, Chauhan A (2016) Incorporation of ultraviolet (UV) absorbing nanoparticles in contact lenses for Class 1 UV blocking. J Mater Chem B 4:327-339. doi:10.1039/c5tb01532d

Guo, Ling Z, Wang C, Zhang X, Xu F (2018) Integration of facile deep eutectic solvents pretreatment for enhanced enzymatic hydrolysis and lignin valorization from industrial xylose residue. Bioresour Technol 265:334-339. doi:10.1016/j.biortech.2018.06.027

Guo, Xue C, Li M, Li X, Ma J (2017) Fabrication of robust, superhydrophobic, electrically conductive and UVblocking fabrics via layer-by-layer assembly of carbon nanotubes. RSC Advances 7:25560-25565. doi:10.1039/c7ra02111a 
Harris AM, Lee EC (2008) Improving mechanical performance of injection molded PLA by controlling crystallinity. Journal of Applied Polymer Science 107:2246-2255. doi:10.1002/app.27261

$\mathrm{Hu} \mathrm{Z}$ et al. (2020) Simultaneous Enhancements of Ultraviolet-Shielding Properties and Thermal Stability/Photostability of Poly(vinyl chloride) via Incorporation of Defect-Rich CeO2 Nanoparticles. Industrial \& Engineering Chemistry Research 59:9959-9968. doi:10.1021/acs.iecr.0c00196

Koetke M, Hubo S, Vargas C, Fonka M, Rosenfeld H, Niemeyer B (2010) New receptors for the detection of organic contaminants in sea water. Procedia Engineering 5:375-380. doi:10.1016/j.proeng.2010.09.126

Li, Li, Bian J, Wu XF, Peng F, Ma MG (2019a) Preparation of organic acid lignin submicrometer particle as a natural broad-spectrum photo-protection agent. Int J Biol Macromol 132:836-843. doi:10.1016/j.ijbiomac.2019.03.177

Li J et al. (2019b) Direct and complete utilization of agricultural straw to fabricate all-biomass films with highstrength, high-haze and UV-shielding properties. Carbohydr Polym 223:115057. doi:10.1016/j.carbpol.2019.115057

Ling Z, Wang K, Liu W, Tang W, Yong Q (2020) Tuning the cellulose nanocrystal alignments for supramolecular assembly of chiral nematic films with highly efficient UVB shielding capability. Journal of Materials Chemistry C 8:8493-8501. doi:10.1039/d0tc01626h

Ling Z, Zhang X, Yang G, Takabe K, Xu F (2018) Nanocrystals of cellulose allomorphs have different adsorption of cellulase and subsequent degradation. Industrial Crops and Products 112:541-549. doi:10.1016/j.indcrop.2017.12.052

Liu Q, Wang S, Zheng Y, Luo Z, Cen K (2008) Mechanism study of wood lignin pyrolysis by using TG-FTIR analysis. Journal of Analytical and Applied Pyrolysis 82:170-177. doi:10.1016/j.jaap.2008.03.007 
Llevot A, Grau E, Carlotti S, Grelier S, Cramail H (2016) From Lignin-derived Aromatic Compounds to Novel Biobased Polymers. Macromolecular Rapid Communications 37:9-28. doi:10.1002/marc.201500474

Neamjan N, Sricharussin W, Threepopnatkul P (2012) Effect of various shapes of ZnO nanoparticles on cotton fabric via electrospinning for UV-blocking. J Nanosci Nanotechnol 12:525-530. doi:10.1166/jnn.2012.5349

Parejo PG, Zayat M, Levy D (2006) Highly efficient UV-absorbing thin-film coatings for protection of organic materials against photodegradation. Journal of Materials Chemistry 16 doi:10.1039/b601577h

Petridis L, Schulz R, Smith JC (2011) Simulation analysis of the temperature dependence of lignin structure and dynamics. J Am Chem Soc 133:20277-20287. doi:10.1021/ja206839u

Sadeghifar H, Venditti R, Jur J, Gorga RE, Pawlak JJ (2016) Cellulose-Lignin Biodegradable and Flexible UV Protection Film. ACS Sustainable Chemistry \& Engineering 5:625-631. doi:10.1021/acssuschemeng.6b02003

Sasani Ghamsari M, Alamdari S, Han W, Park HH (2017) Impact of nanostructured thin $\mathrm{ZnO}$ film in ultraviolet protection. Int J Nanomedicine 12:207-216. doi:10.2147/IJN.S118637

Shankar S, Reddy JP, Rhim JW (2015) Effect of lignin on water vapor barrier, mechanical, and structural properties of agar/lignin composite films. Int J Biol Macromol 81:267-273. doi:10.1016/j.ijbiomac.2015.08.015

Shen X, Du J, Sun J, Guo J, Hu X, Wang C (2020) Transparent and UV Blocking Structural Colored Hydrogel for Contact Lenses. ACS Appl Mater Interfaces 12:39639-39648. doi:10.1021/acsami.0c10763

Wang, Zhang B, Jiang S, Bai H, Zhang S (2019) Use of $\mathrm{CeO}_{2}$ Nanoparticles to Enhance UV-Shielding of Transparent Regenerated Cellulose Films. Polymers (Basel) 11 doi:10.3390/polym11030458 
Wang, Zhou S, Wu L (2012) Stability, UV shielding properties, and light conversion behavior of Eu(BMDM)3@polysiloxane nanoparticles in water and polyurethane films. Materials Chemistry and Physics 137:644-651. doi:10.1016/j.matchemphys.2012.09.070

Williamson CE et al. (2014) Solar ultraviolet radiation in a changing climate. Nature Climate Change 4:434441. doi:10.1038/nclimate2225

Yang W, Wang X, Gogoi P, Bian H, Dai H (2019) Highly transparent and thermally stable cellulose nanofibril films functionalized with colored metal ions for ultraviolet blocking activities. Carbohydr Polym 213:10-16. doi:10.1016/j.carbpol.2019.02.085

Yun S, Kim J, Lee KS (2010) Evaluation of cellulose electro-active paper made by tape casting and zone stretching methods. International Journal of Precision Engineering and Manufacturing 11:987-990. doi:10.1007/s12541-010-0120-2

Zhang WL, Liu ZY, Liu Z, Li FL (2012) Butanol production from corncob residue using Clostridium beijerinckii NCIMB 8052. Lett Appl Microbiol 55:240-246. doi:10.1111/j.1472-765X.2012.03283.x

Zhou Y, Qian Y, Wu S, Zhong X, Huang J, Qiu X (2020) Incorporation of nano lignin reverse micelles on the transparency, UV-blocking and rheological properties of high-density polyethylene films. Holzforschung 74:513-521. doi:10.1515/hf-2019-0091

Zhu R, Liu X, Song P, Wang M, Xu F, Jiang Y, Zhang X (2018) An approach for reinforcement of paper with high strength and barrier properties via coating regenerated cellulose. Carbohydrate Polymers 200:100105. doi:10.1016/j.carbpol.2018.07.069 

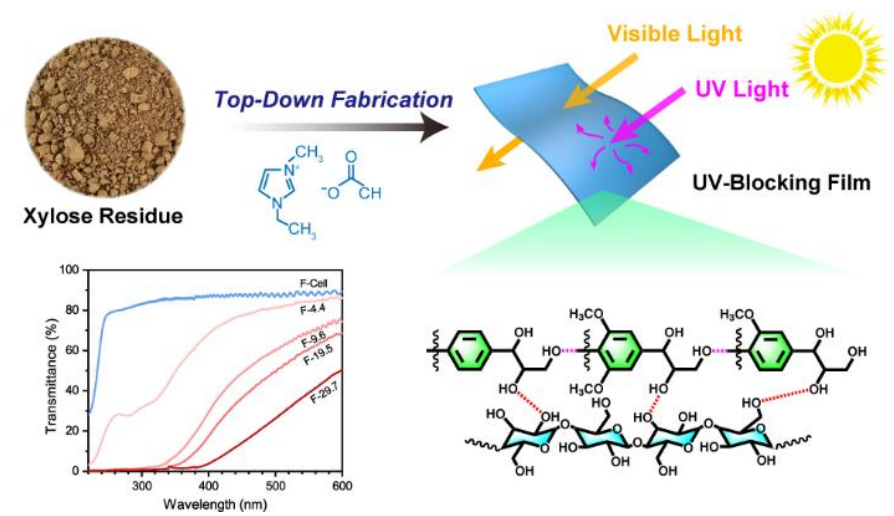


\section{Figures}

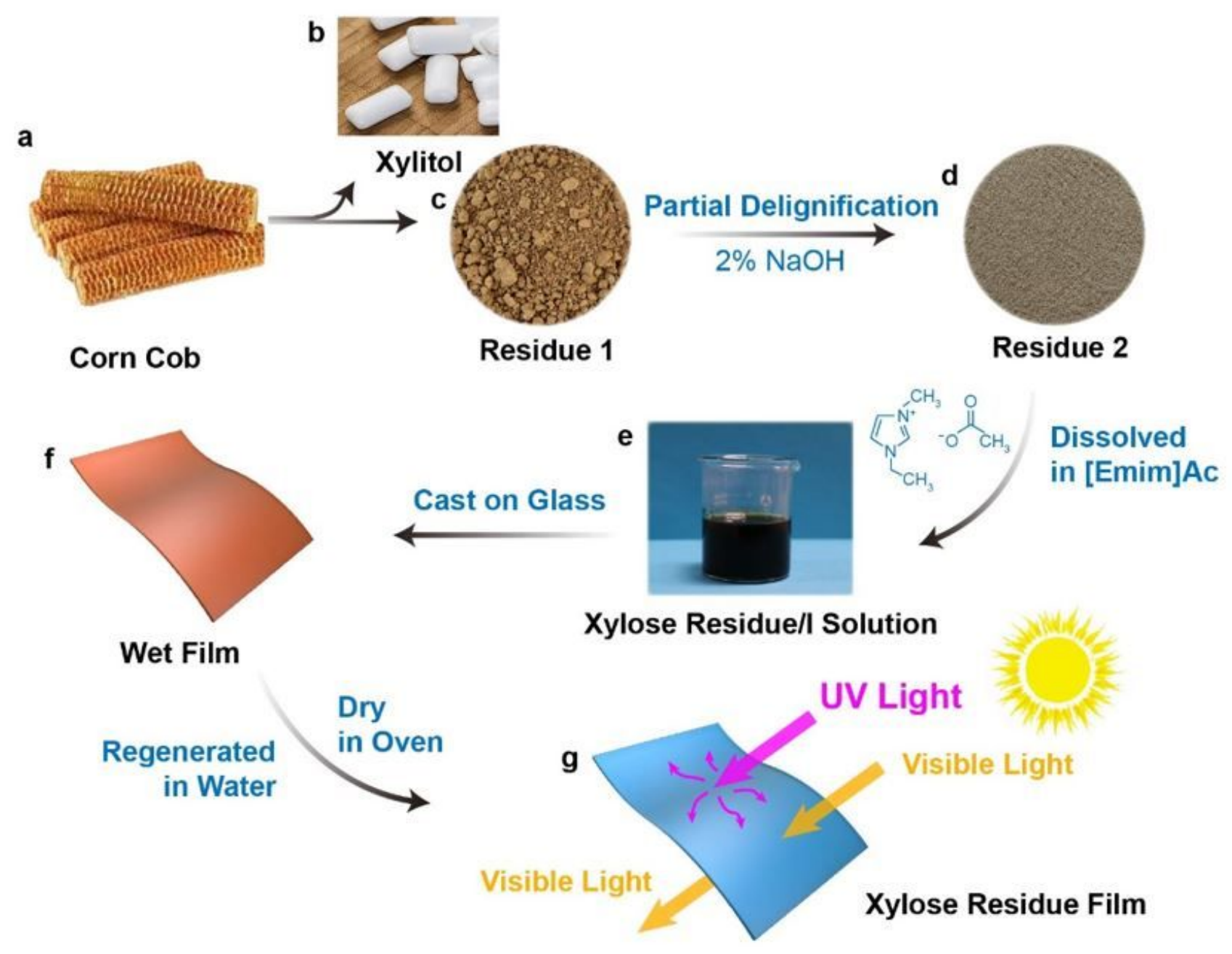

Figure 1

The schemes showing the fabrication process of xylose residue films 


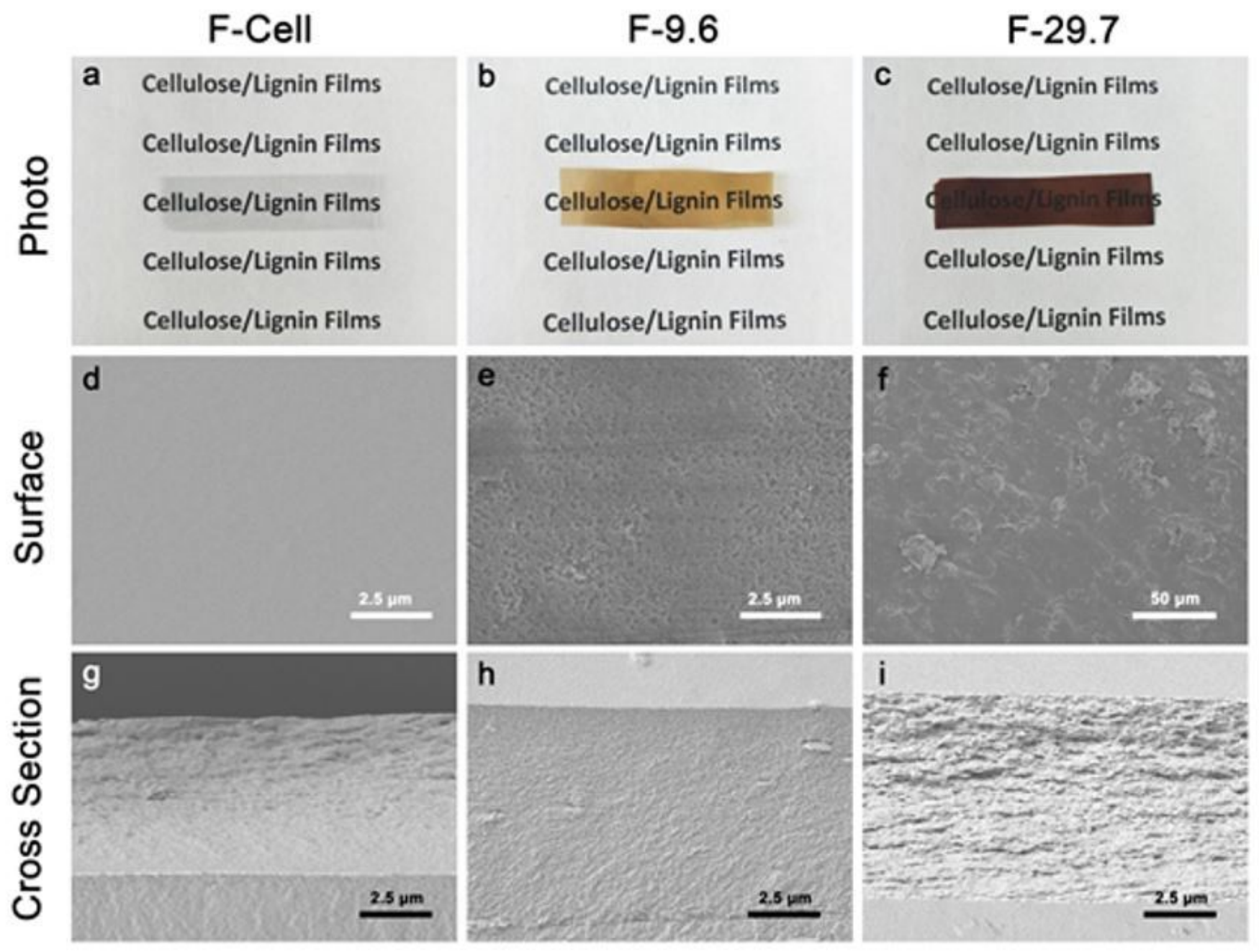

Figure 2

(a-c) Photos of F-Cell, F-9.6, and F-29.7 placed close to the printed pattern underneath. (d-f) The surface morphologies of F-Cell, F-9.6, and F-29.7. (g-i) The cross-sectional morphologies of F-Cell, F-9.6, and F29.7 

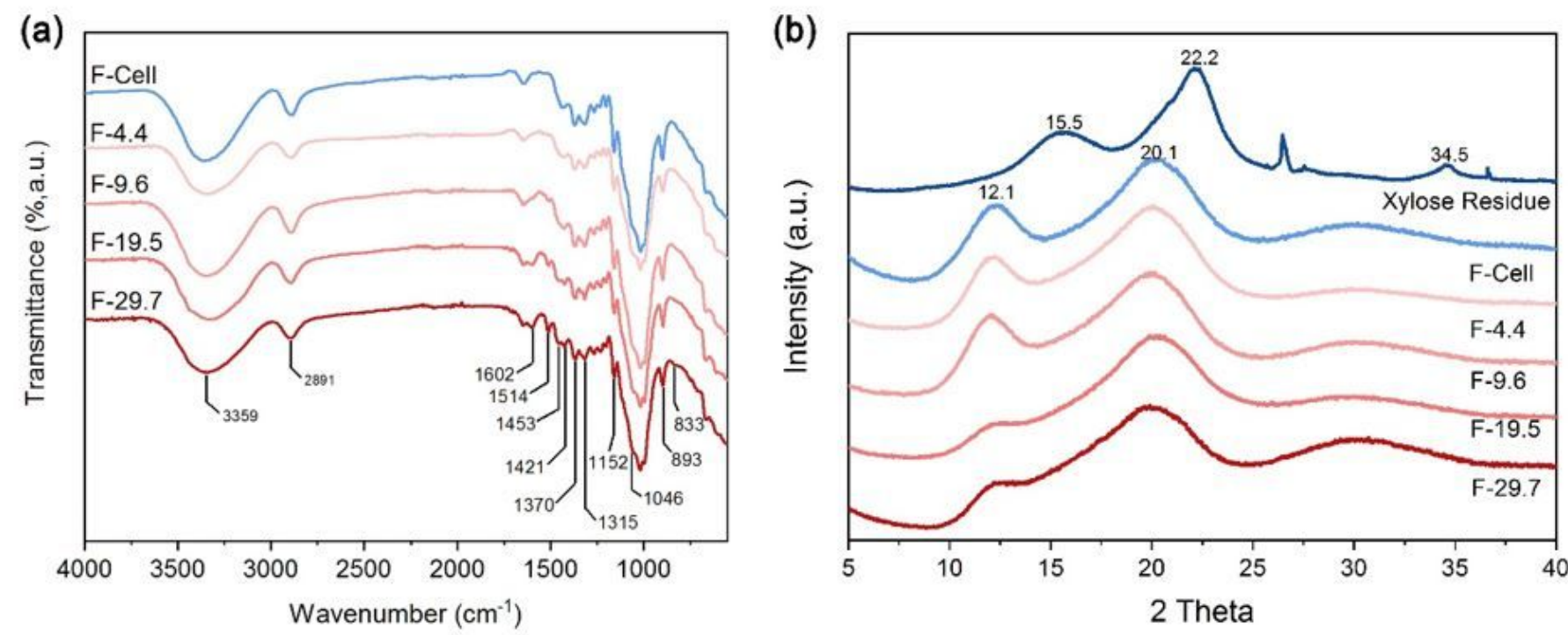

Figure 3

(a) FTIR spectra and (b) XRD patterns of F-Cell, F-4.4, F-9.6, F-19.5, and F-29.7
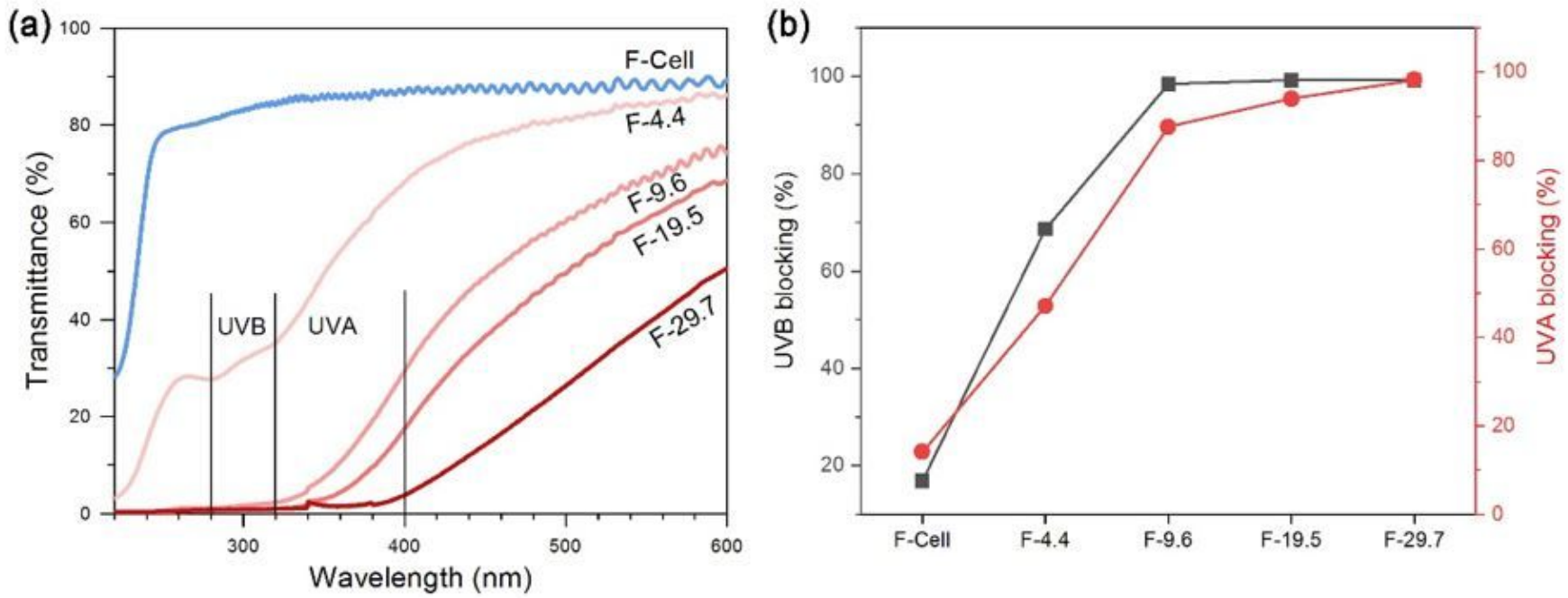

Figure 4

(a) Optical transmission spectra and (b) UV blocking rate of F-Cell, F-4.4, F-9.6, F-19.5, and F-29.7 


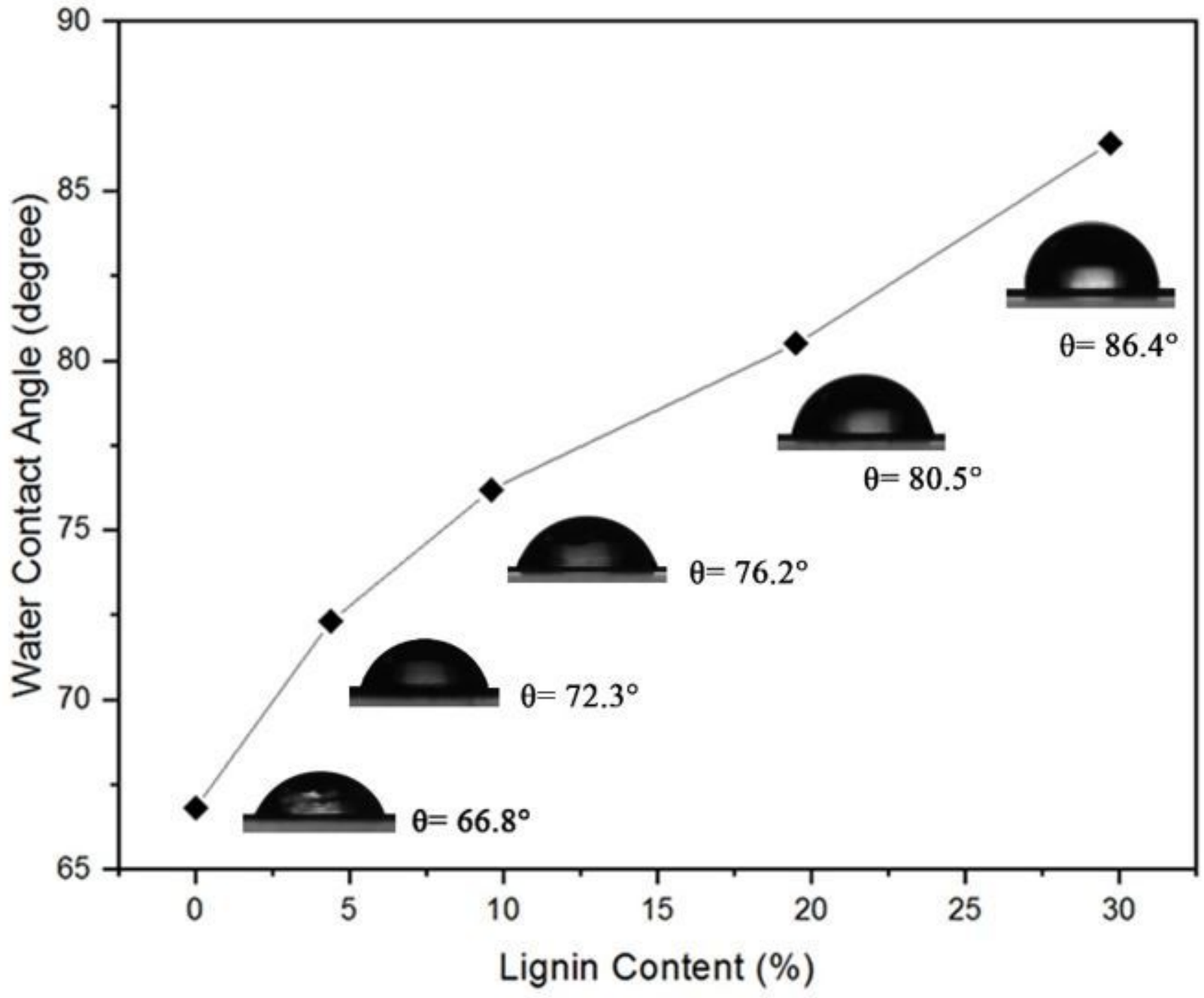

Figure 5

The WCA of F-Cell, F-4.4, F-9.6, F-19.5, and F-29.7 

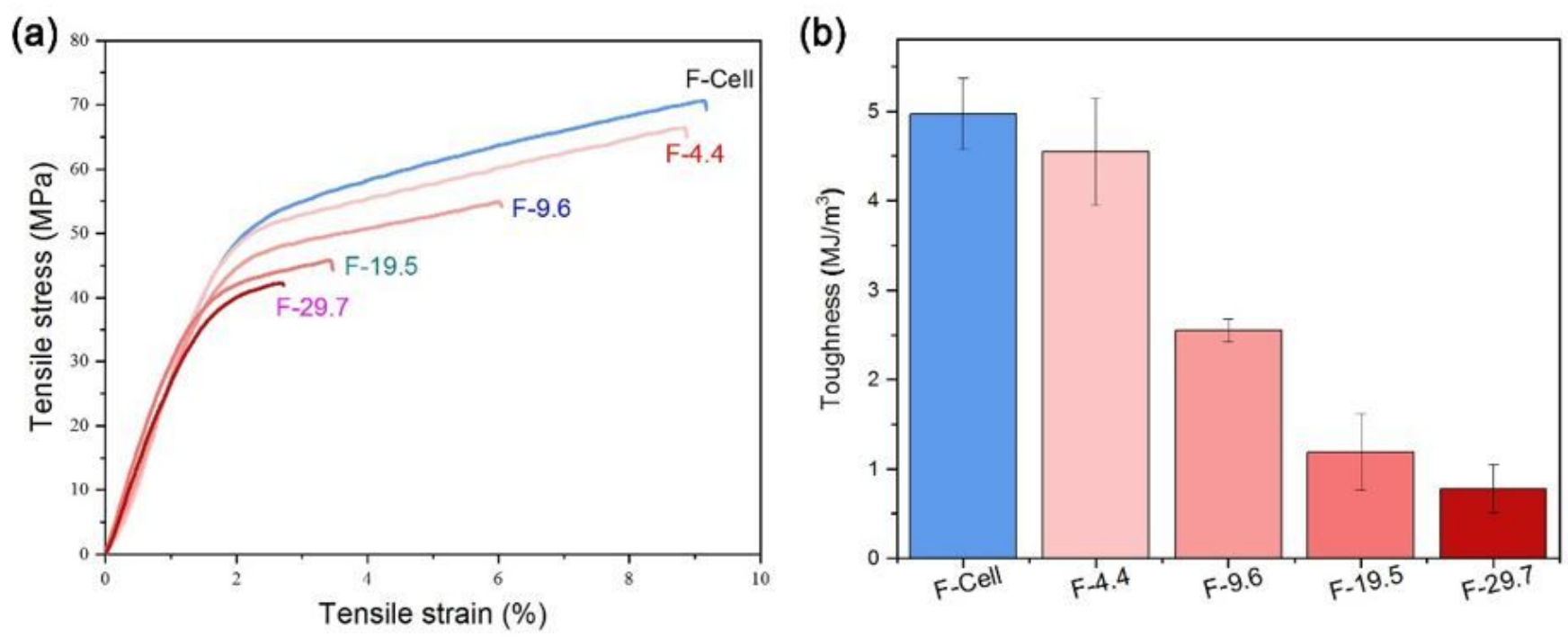

Figure 6

(a)Tensile stress-strain curves and (b) toughness comparison of F-Cell, F-4.4, F-9.6, F-19.5, and F-29.7
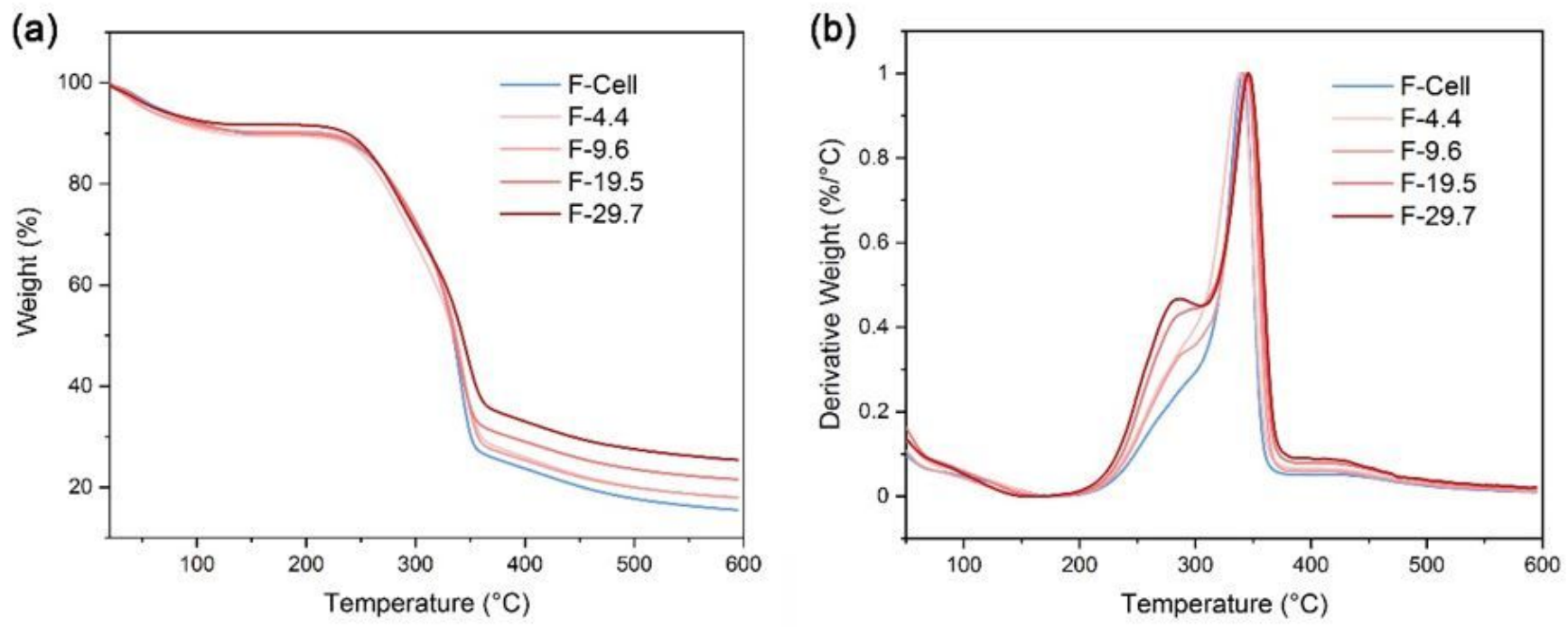

Figure 7

(a)TGA and (b) DTG curves of F-Cell, F-4.4, F-9.6, F-19.5, and F-29.7

\section{Supplementary Files}

This is a list of supplementary files associated with this preprint. Click to download.

- GA.jpg 
- Supplementaryinformation.pdf 